\title{
A Study on Discharge Characteristics by Using MF and RF Power in Remote Dielectric Barrier Discharge
}

\author{
D.J. KIM ${ }^{a, b, *}$, Y.K. SHIM ${ }^{a}$, H.J. KIM ${ }^{c}$ AND J.G. HAN ${ }^{b}$ \\ ${ }^{a}$ Geniatech Inc., Room 810, Hanlla Sigma Valley, 545 Dunchun-daero, Jungwon-gu, Seongnam-si, Gyeonggi-do, \\ South Korea \\ ${ }^{b}$ CAPST, Sungkyunkwan University, 300 ChunChun-dong, Jangan-gu, Suwon 440-746, South Korea \\ ${ }^{c}$ KIST, Center for Spintronics, Hwarangno 14-gil 5, Seongbuk gu, Seoul 136-791, South Korea
}

We have developed an atmospheric pressure plasma apparatus of remote dielectric barrier discharge (RDBD) applicable for a large area. We have systematically studied the characteristics of medium frequency $(\mathrm{MF}, 40 \mathrm{kHz})$ and radio frequency $(\mathrm{RF}, 13.56 \mathrm{MHz})$ discharge using an optical emission spectroscope. Nitrogen $\left(\mathrm{N}_{2}\right)$ and argon (Ar) gases were used in the MF and RF discharge excitation, respectively, in a mixture with clean dry air (CDA). The peak of oxygen radical $\left(\mathrm{O}_{2}^{*}\right)$ appears at $259.3 \mathrm{~nm}$ when the RDBD is employed. Furthermore, intensive peaks are observed at gas ratios of $\mathrm{N}_{2}: \mathrm{CDA}=100: 1$ in $\mathrm{MF}$ excitation and at gas ratios of Ar:CDA=70:0.5 in $\mathrm{RF}$ discharge excitation. On the other hand, the contact angle shows about $5^{\circ}$ in PET samples after the RDBD treatment using the RF and MF discharge excitation. Surface analyses of polyethylene terephthalate (PET) samples were carried out using an atomic force microscope and X-ray photoelectron spectroscope.

DOI: 10.12693/APhysPolA.129.707

PACS/topics: 52.77.Bn

\section{Introduction}

Atmospheric pressure plasma has attracted considerable attention due to the potential applications for pretreatments of plastic painting, semiconductor packaging, liquid crystal display (LCD) wet cleaning, in green- and bio-technology [1-3]. The electrode structure of the atmospheric pressure plasma, such as a remote dielectric barrier discharge (DBD), a direct DBD, and an arc jet [4], varies depending on the application. In the remote DBD, plasma is generated inside the electrode and released outside through a ground electrode, which is applicable for samples sensitive to electric shock. In particular, the remote DBD is a preferable tool for the large area treatment of surface of sensitive substances in semiconductor and display processes.

To date, many studies of atmospheric pressure plasma have been intensively focused on surface treatment using the electrode and surface coating $[5,6]$. Cho et al. reported the effect of the surface treatment employed for vascular grafts [7]. Ma et al. claimed the fabrication of fluorocarbon thin films using a new type of electrode [8]. Lu et al. showed the formation of glow discharge using a brush type electrode for applications of large area surface treatment [9] and have examined the discharge properties by an optical emission spectroscopy (OES) analysis. Moreover, they attempted to remove bacteria and germs using atmospheric pressure plasma of arc jet type or dis-

*corresponding author; e-mail: djkim86@naver.com charge formed by a needle [10-12]. Kim et al. proposed the surface treatment of indium tin oxide (ITO) glasses by means of a plasma jet array [13].

However, the majority of reports have been concentrated on revealing the properties and applications of plasma assisted thin films without studying the properties of the electrode $[14,15]$. In this study, we systematically investigate the properties of discharge as a function of the applied power and the surface properties of polyethylene terephthalate (PET) films used for touch panel electrodes. Radio frequency of $13.56 \mathrm{MHz}$ and medium frequency of $40 \mathrm{kHz}$ were employed to generate the discharge with argon $(\mathrm{Ar})$, nitrogen $\left(\mathrm{N}_{2}\right)$, and compressed air. The discharge properties are explored by OES analysis and the volume of ozone generated as a result of the discharge. An atomic force microscopy (AFM) and X-ray photoemission spectroscopy (XPS) are used to examine the changes of the properties of the PET films after surface treatment.

\section{Experimental}

The electrode with the size of $500 \times 50 \mathrm{~mm}^{2}$ for the remote DBD was prepared. Figure 1 shows the structure of the electrode used in this study. The alumina $\left(\mathrm{Al}_{2} \mathrm{O}_{3}\right)$ was used as the electrode material. Aluminum was used for the case of electrodes with the holes for the discharge gas emission. The bottom plate is grounded for the charged particles not to escape outside, preventing electrical damage of the sample surface by the charged particles. 


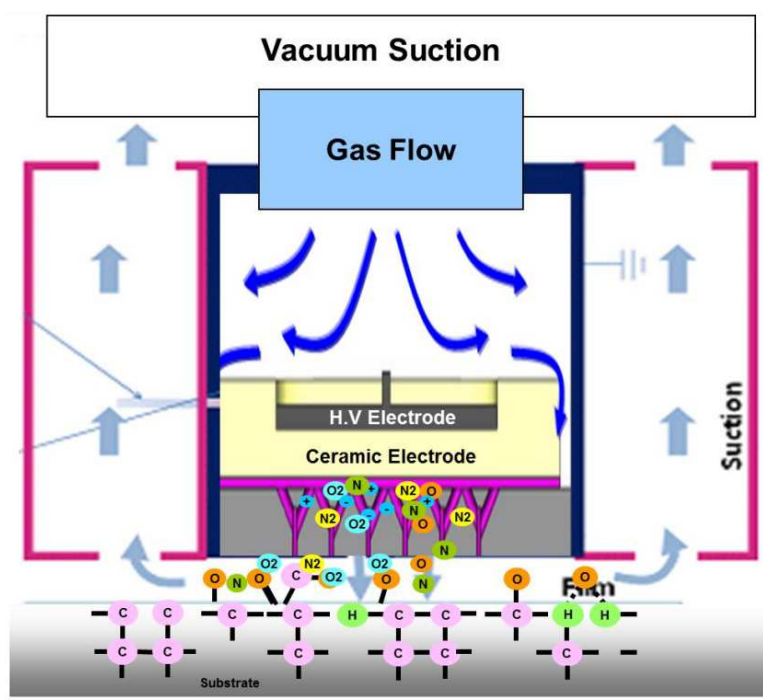

Fig. 1. Schematic drawing of RDBD electrode.

Mass flow controllers (MFCs) were employed to control the ratio of the gases. The feeding speed of samples was kept constant at $60 \mathrm{~mm} / \mathrm{min}$. Discharge characteristics are analyzed using a SM240-spectrometer (Spectral Products Ltd.) which can measure between $200 \mathrm{~nm}$ and $1050 \mathrm{~nm}$. PET films used for touch panels are analyzed by AFM and XPS after the atmospheric pressure plasma treatment.

\section{Results and discussion}

\subsection{OES analysis for RF and MF excitation power}

Ar was supplied as the discharge gas because voltage for $\mathrm{RF}$ is relatively low. The voltage range between 500 and $600 \mathrm{~V}$ is applied for RF power in this study. A high applied voltage of $10 \mathrm{kV}$ in MF power leads to the preferable use of $\mathrm{N}_{2}$ gas [16].

It is known that band at $259.3 \mathrm{~nm}$ is originated from $\mathrm{O}_{2}^{*}$ radical [17]. For the purpose of cleaning using atmospheric pressure plasma, $259.3 \mathrm{~nm}$ of $\mathrm{O}_{2}^{*}$ radical is more effective than $321.0 \mathrm{~nm}$ due to a better reaction effect. Figure $2 \mathrm{a}$ shows the discharge properties of $\mathrm{O}_{2}^{*}$ and $\mathrm{O}_{2}^{+}$ in MF power.

As shown in Fig. 2b, the intensive peaks are observed at the Ar:CDA ratios of 50:0.3, 70:0.5, and 100:0.7 at the RF power of $250 \mathrm{~W}$. Although the amount of CDA changes with respect to Ar gas at different process conditions, the best discharge is obtained at the ratio of 100:0.7. In particular, the highest peak from the 70:0.5 ratio indicates that the optimum Ar gas amount exists, depending on the electrode property.

Figure 2c shows the results of spectral analysis using $\mathrm{MF}$ power with the mixture of $\mathrm{N}_{2}$ and CDA gases. It is clear that the $\mathrm{O}_{2}^{*}$ peak at $259.3 \mathrm{~nm}$ changes with respect to the amount of supplied CDA and $\mathrm{O}_{2}^{+}$peak at $321.0 \mathrm{~nm}$. Both $\mathrm{O}_{2}^{*}$ and $\mathrm{O}_{2}^{+}$peaks are observed from the large electrode of $500 \times 50 \mathrm{~mm}^{2}$ and the highest peaks appear at $\mathrm{N}_{2}$ :CDA of 100:1. The highest peak intensity appears at
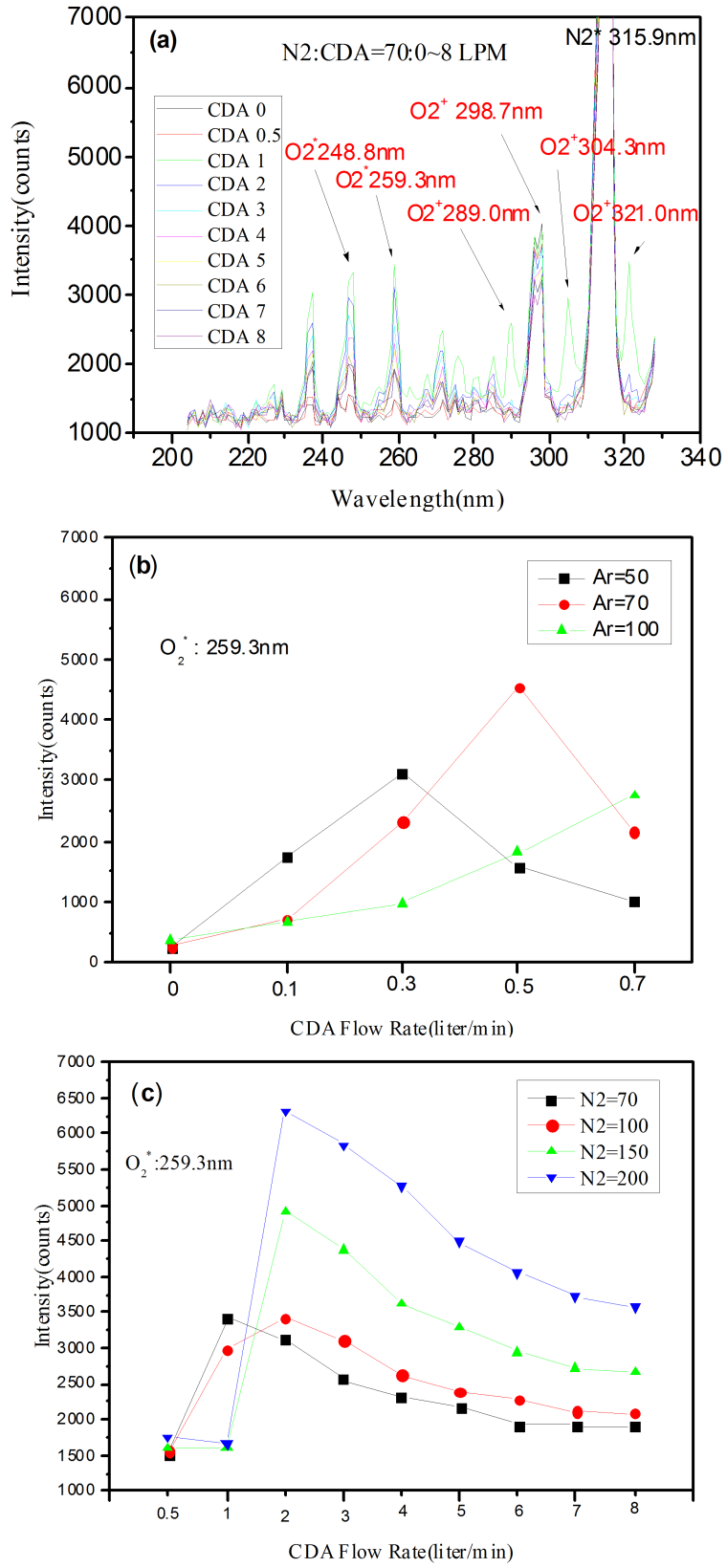

Fig. 2. OES spectral analysis of RF and MF discharge (a) OES peaks of $\mathrm{O}_{2}$ ions and radicals in MF discharge, (b) intensity of $\mathrm{O}_{2}$ radical $(259.3 \mathrm{~nm})$ in $\mathrm{RF}$ discharge using Ar flow, (c) intensity of $\mathrm{O}_{2}$ radical $(259.3 \mathrm{~nm})$ in $\mathrm{MF}$ discharge using $\mathrm{N}_{2}$ flow.

the CDA amount of $2 \mathrm{lpm}$. Figure 2c shows that peak intensity at $259.3 \mathrm{~nm}$ becomes strongest with $\mathrm{N}_{2}$ of $200 \mathrm{lpm}$ and CDA of $2 \mathrm{lpm}$.

\subsection{Surface characterization of PET samples}

Figure 3 illustrates the XPS analysis results showing the C1s changes in the PET films before (Fig. 3a) and after the plasma treatments (Fig. 3b and c) which is relevant for the contact angle and the adhesion. $\mathrm{Al} \mathrm{K}_{\alpha} \mathrm{X}$-ray source was employed in the analysis [18]. Figure 3b shows that plasma treatment by $\mathrm{RF}$ power enhances $\mathrm{C}=\mathrm{O}$ bond peak at $288.3 \mathrm{eV}$ and reduces $\mathrm{C}-\mathrm{O}$ peak at $286.1 \mathrm{eV}$. It is 

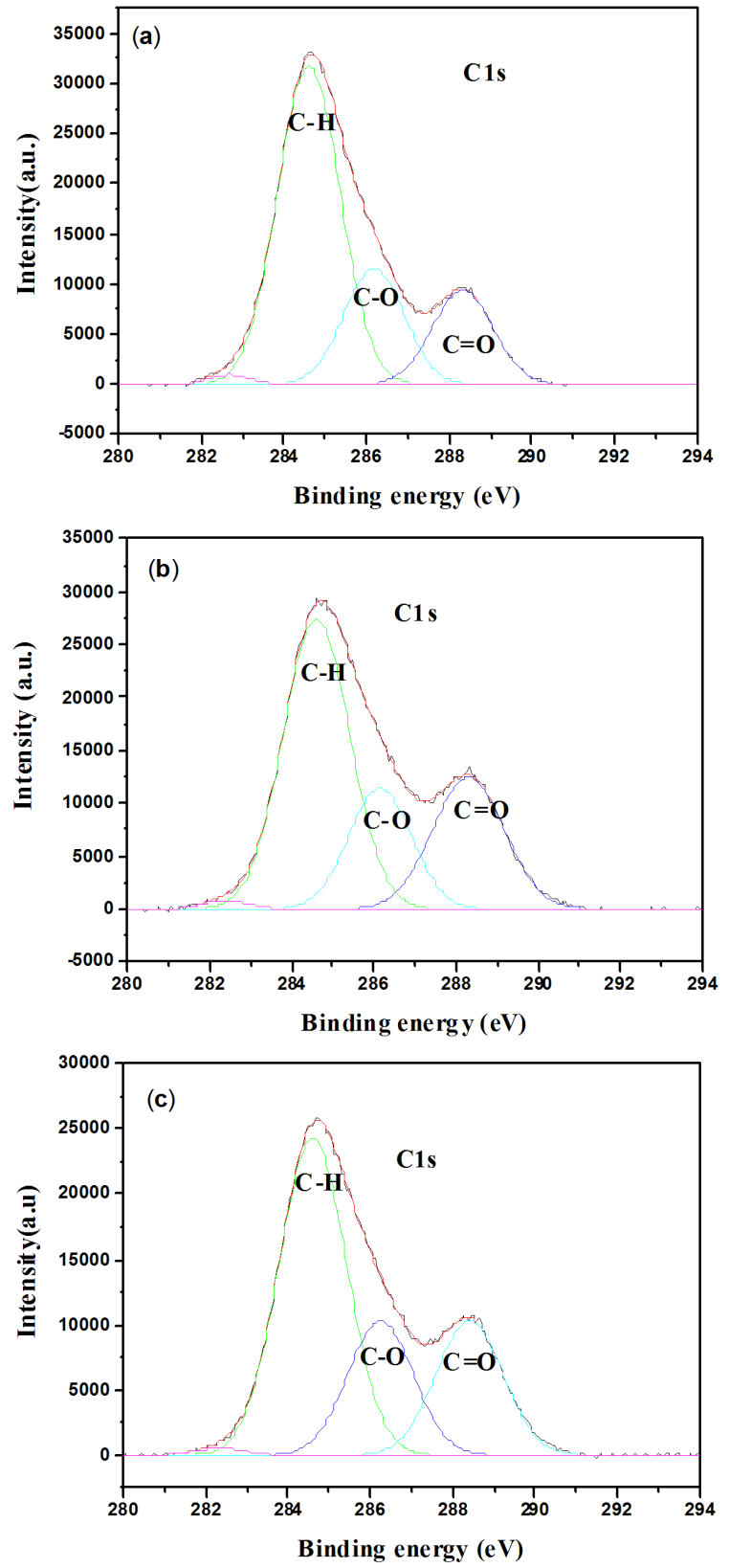

Fig. 3. C1s peak of untreated (a), RF treated (b) and MF treated (c) PET.

evident that the number of $\mathrm{C}=\mathrm{O}$ bonds in $\mathrm{RF}$ treated PET is much larger than in MF treated sample, shown in Fig. 3c. Moreover, treatment using RF clearly improves the $\mathrm{O}=\mathrm{C}$ bond at $531.4 \mathrm{eV}$ compared to $\mathrm{O}-\mathrm{C}$ at $533.0 \mathrm{eV}$. This experimental result can be explained by the postulation that weak $\mathrm{O}-\mathrm{C}$ bonds in $\mathrm{O}-\mathrm{C}=\mathrm{O}$ structures are broken by the plasma treatment, leaving exclusively $\mathrm{C}=\mathrm{O}$ bonds. $-\mathrm{C}=\mathrm{O}-$ in $\mathrm{PET}$ belongs to a carbonyl group, soluble in water, resulting in low water contact angles. The larger number of $\mathrm{C}=\mathrm{O}$ bonds in $\mathrm{RF}$ treated PET is explained by the larger ionization rate of gases due to $\mathrm{RF}$ and a better reaction with PET surface due to stronger $\mathrm{O}_{2}$ dissociation of CDA.

Table I summarizes phase and morphology changes of PET surfaces before and after the discharge treatment.

After the treatment surface morphology significantly changes. Specifically, $R_{a}$ of PET surface increases after $\mathrm{RF}$ treatment due to more intensive reaction with $\mathrm{O}_{2}^{*}$ radical. As indicated in Table I, $R_{p v}$ value of $\mathrm{RF}$ treated PET surface is found to be $56.56 \mathrm{~nm}$ which is much higher than that of MF treated PET $(53.43 \mathrm{~nm})$. Also $R_{a}$ values of RF treated surface are $6.78 \mathrm{~nm}$. This is presumably due to more intensive reaction due to higher ionization in RF. The RF treatment leads to the large amount of $\mathrm{O}_{2}^{*}$ radical favorable for better surface reaction, resulting in roughness of the PET surface. This is in good agreement with the XPS results showing a larger amount of $\mathrm{C}=\mathrm{O}$ with binding energy changes.
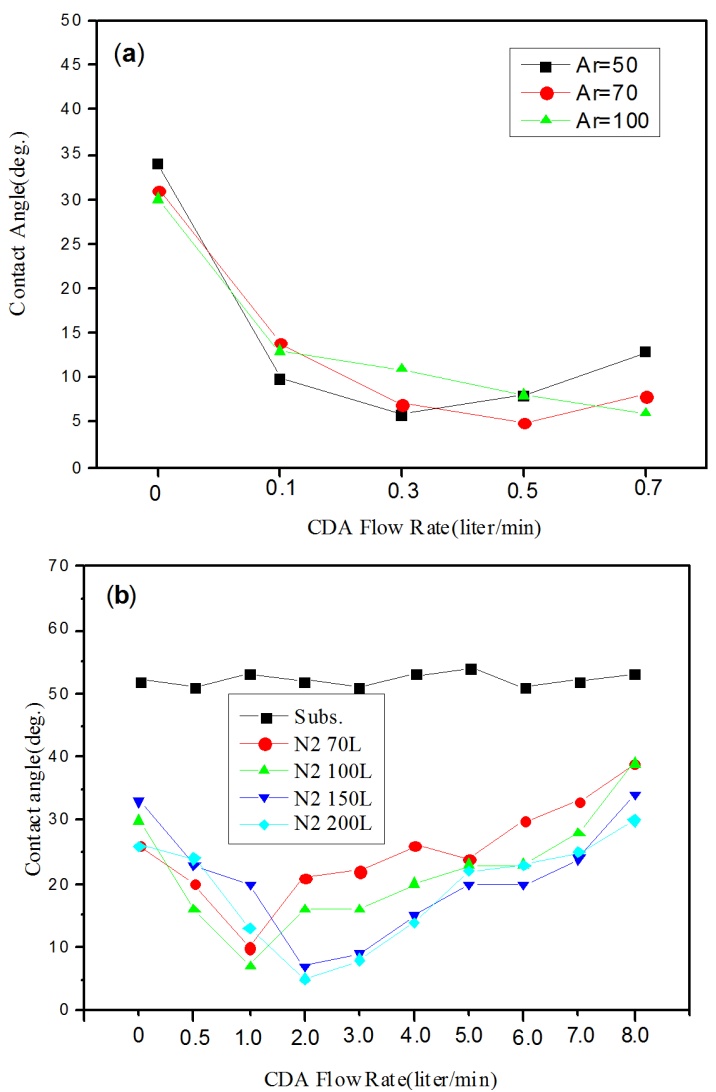

Fig. 4. Contact angle of plasma treated PET in RF and MF discharge. (a) Changes of contact angle in RF treated PET using Ar flow. (b) Changes of contact angle in MF treated PET using $\mathrm{N}_{2}$ flow.

Figure 4 displays the contact angels measured at each gas mixture concentration, which exactly correspond to the results of OES analysis. Figure 4a shows that water contact angle in RF treated PET is less than $5^{\circ}$ at $70 \mathrm{lpm}$ of $\mathrm{Ar}$ and $0.5 \mathrm{lpm}$ of $\mathrm{CDA}$ while it is $10^{\circ}$ at 0.3 and $0.7 \mathrm{lpm}$ of $\mathrm{CDA}$, suggesting that the reaction with the PET becomes more active and the contact angle decreases as the peak intensity of $\mathrm{O}_{2}^{*}$ radical increases as observed in OES analysis. Furthermore, Fig. 4b shows that the contact angle in MF-treated PET is $7^{\circ}$ when the ratio of $\mathrm{N}_{2}$ and $\mathrm{CDA}$ is $100 \mathrm{lpm}$ and $1 \mathrm{lpm}$, respectively, while the lowest contact angle is $5^{\circ}$ at $\mathrm{N}_{2}$ :CDA ratio of 200:2. 
TABLE I

Peak intensity comparison between C1s and O1s from XPS and AFM data.

\begin{tabular}{|c|c|c|c|c|c|c|}
\hline & & $\begin{array}{c}\text { Bonding } \\
\text { state }\end{array}$ & \begin{tabular}{|c|} 
Binding \\
energy $[\mathrm{eV}]$
\end{tabular} & $\begin{array}{c}\text { Intensity } \\
\text { (PET Subs.) }\end{array}$ & $\begin{array}{r}\text { Intensity } \\
\text { (by RF) }\end{array}$ & $\begin{array}{r}\text { Intensity } \\
\text { (by MF) }\end{array}$ \\
\hline \multirow{3}{*}{$\begin{array}{l}\text { C1s } \\
\text { peak }\end{array}$} & Benzene ring & $\mathrm{C}-\mathrm{H}$ & 284.6 & 31.770 & 27.411 & 24.331 \\
\hline & Carbon & $\mathrm{C}-\mathrm{O}$ & 286.1 & 11.574 & 11.413 & 10.296 \\
\hline & Carbonyl bonds & $\mathrm{C}=\mathrm{O}$ & 288.3 & 9.358 & 12.437 & 10.279 \\
\hline \multirow{2}{*}{$\begin{array}{l}\text { O1s } \\
\text { peak }\end{array}$} & & $\mathrm{O}=\mathrm{C}$ & 531.4 & 24.281 & 37.713 & 27.904 \\
\hline & & $\mathrm{O}-\mathrm{C}$ & 533.0 & 22.873 & 28.374 & 26.634 \\
\hline & AFM & \multicolumn{2}{|r|}{$\begin{array}{l}R_{a} \\
R_{p v}\end{array}$} & $\begin{array}{c}2.742 \\
36.637\end{array}$ & $\begin{array}{l}6.781 \\
56.56\end{array}$ & $\begin{array}{c}6.151 \\
53.431\end{array}$ \\
\hline
\end{tabular}

\section{Conclusions}

In this study, we have fabricate the large size electrode of $500 \times 50 \mathrm{~mm}^{2}$ and have characterized PET surfaces with respect to corresponding power and gas employed.

\section{Acknowledgments}

This work was supported by the National Research Foundation (NRF) grant funded (2015004870) and Small Business Technology Innovation Development Project 2014 (S2165804) by Korea government.

1. The discharge at RF and MF excitation has the different optimum ratio of the gas mixture according to the peak of $259.3 \mathrm{~nm}\left(\mathrm{O}_{2}^{*}\right)$ in OES analysis. The RF excitation shows the best discharge effect at Ar:CDA ratio of 70:0.5 while MF excitation does at $\mathrm{N}_{2}$ :CDA ratio of $100: 1$.

2. XPS analysis reveals that the RF treated PET has a larger amount of $\mathrm{C}=\mathrm{O}$ bonds of $288.3 \mathrm{eV}$ and $\mathrm{O}=\mathrm{C}$ binding of $531.4 \mathrm{eV}$.

3. The higher ionization rate of RF discharge results in higher surface roughness $\left(R_{a}=6.78 \mathrm{~nm}\right)$ of the PET surface after plasma treatment.

4. After the plasma treatment, the contact angles of PET are found to be $5^{\circ}$, which is a confirmation of a very good cleaning effect.

\section{References}

[1] R.A. Sailer, A. Wagner, Ch. Schmit, N. Klaverkamp, D.L. Schulz, Surf. Coat. Tech. 203, 835 (2008).

[2] Chang Heon Yi, Chang Hyun Jeong, Yong Hyuk Lee, Young Wook Ko, Geun Young Yeom, Surf. Coat. Tech. 177-178, 711 (2004).
[3] A. Pamreddy, D. Skácelová, M. Haničinec, P. St’ahel, M. Stupavská, M. Černák, J. Havel, Surf. Coat. Tech. 236, 326 (2013).

[4] K.D. Weltmann, E. Kindle, T. von Woedtke, M. Hahnel, M. Stieber, R. Brandenburg, Pure Appl. Chem. 82, 1223 (2010).

[5] H.-R. Lee, D.-J. Kim, K.-H. Lee, Surf. Coat. Tech. 142-144, 468 (2001).

[6] D.-J. Kim, Y.-K. Kim, J.-G. Han, J. Kor. Inst. Surf. Eng. 44, 50 (2011).

[7] Y.-K. Cho, D.-W. Park, H.-B. Kim, H.-R. Lim, H.Y. Park, H.-J. Kim, D.-G. Jung, Appl. Surf. Sci. 296, 79 (2014).

[8] Wei Chun Ma, Ching Yuan Tsai, Chung Huang, Surf. Coat. Tech. 259, 290 (2014).

[9] X. Lu, M. Laroussi, V. Puech, Plasma Sources Sci. Technol. 21, 034005 (2012).

[10] X. Lu, S. Wu, P.K. Chu, D. Liu, Y. Pan, Plasma Sources Sci. Technol. 20, 065009 (2011).

[11] X. Pei, X. Lu, J. Liu, D. Liu, Y. Yang, K. Ostrikov, P.K. Chu, Y. Pan, J. Phys. D: Appl. Phys. 45, 165205 (2012).

[12] ShuQun Wu, Zhan Wang, QuanJun Huang, XinPei Lu, Yuan Pan, IEEE T. Plasma Sci. 39, 1489 (2011).

[13] J.-Y. Kim, J. Ballato, S.-O. Kim, Plasma Processes Polym. 9, 253 (2012).

[14] F. Massines, N. Gherardi, A. Fornelli, S. Martin, Surf. Coat. Tech. 200, 1855 (2005).

[15] M. Moravej, R.F. Hicks, Chem. Vap. Deposition 11, 469 (2005).

[16] A. Grill, Cold Plasma Materials Fabrication: From Fundamentals to Applications, Wiley-IEEE, 1994, p. 28.

[17] R.W.B. Pearse, A.G. Gaydon, The Identification of Molecular Spectra, 4th ed., Chapman and Hall, 1984 reprinted, p. 258.

[18] M. Bou, J.M. Martin, Th. Le Mogne, L. Vovelle, Appl. Surf. Sci. 47, 149 (1991). 